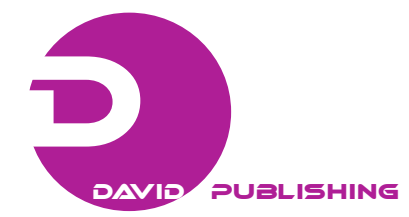

\title{
Self-determination, Self-efficacy and Self-regulation in School: A Longitudinal Intervention Study With Primary School Pupils
}

\author{
Daniela Martineka, Ulrike Kipman ${ }^{a}$
}

\begin{abstract}
The study documents an intervention programme based on the Self-determination Theory of Deci and Ryan (2000) with school beginners in an Austrian primary school with the aim to improve perceived self-determination and academic self-regulation of school beginners. For two years, teachers were guided by a team of educational scientists to design challenging autonomous learning settings and to foster self-determined academic regulation. Before and after the intervention, about 100 pupils were questioned concerning their well-being in school, perceived autonomy support, their academic self-regulation, and school-related self-efficacy. Teachers' autonomy support decreased during the first year but remained stable from then on. Pupils' intrinsic regulation, as well as their introjected and external regulation and their self-efficacy, decreased throughout the intervention but identified regulation remained stable. The results indicate that perceived self-determination, self-determined academic regulation, and self-efficacy contribute to school-related well-being and offer interesting recommendations for improving the climate in schools for pupils and teachers.
\end{abstract}

\section{Keywords}

Self-determined learning, academic self-regulation, self-efficacy, early education

Numerous studies stress the relevance of academic intrinsic motivation for learning processes right from the beginning of education in schools (cf. Boggiano 1998; Miserandino 1996; Bouffard et al. 2003; Lepper, Corpus, and Iyengar 2005; Spinath and Steinmayr 2008), yet extrinsic types of motivation seem inevitable elements of education (Reeve 2009). Building on the multidimensional approach of the Self-Determination Theory (SDT) by Deci and Ryan (2012) and on empirical studies focusing on the academic motivation of primary school children (Gottfried 1990; Skinner et al. 2009; Dresel et al. 2010; Corpus and Wormington 2014), the authors developed an intervention programme for school beginners and guided teachers and pupils for a period of two years.
In so doing, the authors were able to collect data concerning perceived autonomy, academic self-regulation, subjective well-being, and school-related self-efficacy of a target group that is rarely analysed-the six to 10 years old primary pupils in grades one to three.

aUniversity of Salzburg, Austria

\section{Correspondent Author:}

Daniela Martinek, School of Education/Educational Sciences, University of Salzburg, Erzabt-Klotz-Str. 1, 5020 Salzburg, Austria 


\section{SELF-DETERMINATION AND SUBJECTIVE WELL-BEING IN SCHOOL}

Self-determination plays an important role for successful learning (Ryan and Deci 2013) and being able to act self-determinedly is conducive for academic achievement, for positive classroom functioning and pupils' psychological well-being (Deci and Ryan 2000; Jang et al. 2009). The way teachers interact with their pupils and how they initiate and organise learning processes has an essential impact on perceived autonomy (Deci and Ryan 2008) and educators can actively use autonomy supportive strategies in class to foster self-determined involvement (Chatzisarantis and Hagger 2009; Tessier, Sarrazin, and Ntoumanis 2010). Educational research provides empirically well-tested methods that are effective to promote self-determination (Su and Reeve 2011). In addition to concentrating on individual interests, the provision of significant choices, making structures and arrangements clear, providing meaningful rationales and a considerate way of interacting with pupils, including the use of non-controlling language and openness toward students' perceptions and attitudes, are fundamental strategies to support self-determination in class (Reeve and Cheon 2014). According to intervention studies, teachers can be trained to use these methods effectively (Reeve, Deci, and Ryan 2004; Chatzisarantis and Hagger 2009; Tessier et al. 2010; Cheon and Reeve 2013) and research indicates that an autonomy supportive teaching style contributes to well-being (Vansteenkiste et al. 2004) and to developing autonomous forms of academic self-regulation (Sierens et al. 2009; Vansteenkiste et al. 2009; Jang, Reeve, and Deci 2010; Soenens et al. 2012).

\section{ACADEMIC SELF-REGULATION AND AUTONOMY SUPPORT}

According to SDT, pupils have an evolved tendency to grow and learn (Reeve, Deci, and Ryan 2004). The prototype of autonomous behaviour is intrinsic motivation, when pupils engage in activities because they are spontaneously interesting and enjoyable without the requirements of separable consequences. When confronted with external demands, learners are inherently motivated to integrate the regulation of extrinsically motivated activities within themselves (Ryan 1993). In this proactive process, external regulations are transformed into regulations by the self, and supportive as well as nurturing social conditions in class can contribute to this internalisation (Deci et al. 1994).

With respect to extrinsic motivation, the multidimensional SDT approach distinguishes different types: external, introjected, identified, and integrated regulation (Deci et al. 1994). Behaviour regulated through external means such as constraints, punishment, or rewards corresponds with external regulation. Introjected regulation occurs when a pupil accepts a regulation or contingency without accepting it as his or her own and refers to behaviour that is driven by internal pressure, e.g. anxiety or emotions of self-esteem (Ryan and Connell 1989). Pupils understanding the value of uninteresting behaviours and being willing to accept responsibility for their behaviours experience identified regulation and, if learners are able to fully endorse the requested behaviours with their self-concept, the behavioural regulation is integrated (Deci and Ryan 2016).

Learning environments that support autonomy contribute to maintaining and developing intrinsic, integrated, and identified regulations, which are considered to be (rather) self-determined types of motivation, whereas pressure-inducing and controlling teachers foster introjected and external regulations, which are (rather) controlled types of motivation (Deci and Ryan 1987; Ryan and Stiller 1991; Vallerand, Fortier, and Guay 1997; Deci, Koestner, and Ryan 1999). A convincing line of educational 
research documents that self-determined regulation corresponds with positive consequences, such as: engagement (Jang et al. 2010); conceptual learning (Grolnick and Ryan 1987); achievement and mastery orientation (Gurland and Grolnick, 2005; Pelletier et al. 2013); perceived competence and better performance (Grolnick, Ryan, and Deci 1991; Fortier, Vallerand, and Guay 1995; Miserando 1996; De Naeghel et al. 2012); well-being (Kasser and Ryan 1996) and higher self-efficacy (Thøgersen-Ntoumani and Ntoumanis 2006).

\section{PUPILS' ACADEMIC SELF-EFFICACY AND SELF-DETERMINED REGULATION}

According to Bandura's Social Cognitive Theory (1997), academic self-efficacy beliefs refer to pupils' judgments concerning their capability of accomplishing a task or succeeding in an activity. Self-efficacy beliefs determine pupils' choices, their efforts, their persistence, and their perseverance when facing difficult challenges, and these beliefs are nurtured by interpreting information from four primary sources: mastery experience, vicarious experience, social persuasions, and physiological and emotional states (Bandura 1986). Research has determined that self-efficacy influences academic achievement across academic areas and levels (Pajares and Urdan 2006) and it is associated with motivational constructs such as causal attributions, self-concept, optimism, achievement goal orientation, academic help-seeking, anxiety, and value (Usher and Pajares 2008). Moreover, pupils who are confident in their academic capabilities engage in more self-regulatory strategies that promote success in school (Schunk and Pajares 2005). The self-beliefs of school beginners are likely to be most malleable and to have an impact on the structure of subsequent efficacy beliefs (Bandura 1997).

From a conceptual standpoint, the basic psychological need for competence, defined within SDT, can be related to self-efficacy, although self-efficacy beliefs represent domain-specific perceptions of competence and are instrumental for goal attainment (Bandura 1997), whereas the basic psychological need for competence, as defined within SDT, rather refers to feeling effective in interactions with the social environment and being able to explore one's capacities (Ryan and Deci 2002). Relating these two concepts to each other, it seems feasible that if supporting autonomy fosters the satisfaction of the basic psychological needs (Deci and Ryan 2000), then experiencing self-determination-with respect to individual academic self-regulation or teachers' support—should consequently contribute to higher self-efficacy.

\section{THE PRESENT STUDY}

In the present research, a team of primary school teachers and educational scientists cooperated in order to design and establish an innovative educational concept with a special emphasis on self-determined learning ( $\mathrm{SE}^{3} \mathrm{~W}$-self-determination, self-regulation, self-efficacy, and well-being). The authors collected longitudinal data concerning perceived self-determination, academic self-regulation, self-efficacy, and subjective well-being from 131 pupils from grades one to three in an Austrian primary school. In line with the main intervention objective, the authors hoped to achieve constant results concerning the perception of autonomy support (Reeve 2011) and positive development of the academic self-regulation of the participating pupils (Bandura 1997; Vallerand et al. 1997; Deci et al. 1999; Schunk and Pajares 2005). Based on prior findings (Thøgersen-Ntoumani and Ntoumanis 2006; Sierens et al. 2009; Vansteenkiste et al. 2009; Jang et al. 2010; Soenens et al. 2012), the authors assumed that perceived autonomy, self-determined types of academic regulation, and self-efficacy contribute to subjective well-being. In addition to monitoring the individual development of learners, they also analysed 
differences and transformations at class level in order to gain further insights concerning the impact of teaching styles on pupils' motivational development (Hattie 2009).

\section{METHOD}

\section{Sample and Procedure}

One hundred and forty-eight (148) pupils aged between six and nine years old in the pre-test $(\mathrm{M}=$ $6.96, \mathrm{SD}=.728)$ and aged between six and 10 years old $(\mathrm{M}=7.90, \mathrm{SD}=1.04)$ in the post-test from one primary school in Austria participated in this study called $\mathrm{SE}^{3} \mathrm{~W}$. Seventy-five pupils participated in the pre-test and the post-test sessions. Pupils answered questions concerning perceptions of autonomy, academic self-regulation, subjective well-being, and self-efficacy in both sessions. Due to the elementary school basic reading competencies of the students, test sessions were guided by trained interviewers.

\section{Instruments}

Self-determination. Students' self-determination was assessed by applying the 6-item scale adapted from the Learning Climate Questionnaire (Black and Deci 2000). Cronbach's $\alpha$ in the original 15-item instrument ranges between .93 and .96 (Black and Deci 2000; Williams and Deci 1996). Answers were provided on a 5-point Likert scale ranging from "not at all true" (1) to "very true" (5). Mean scores were calculated over all items to measure self-determination.

Academic self-regulation. Students' academic self-regulation was assessed using 12 items adapted from Müller, Hanfstingl, and Andreitz (2007) based on the Academic Self-regulation Questionnaire according to Ryan and Connell (1989). Cronbach's $\alpha$ ranges from .75 for extrinsic regulation to .92 for intrinsic regulation (Müller et al. 2007). Answers were given on a 5-point Likert scale ranging from "not at all true" (1) to "very true" (5). The authors calculated mean representing the four different types of academic self-regulation: intrinsic regulation, identified regulation, introjected regulation, and external regulation (Müller et al. 2007).

Self-efficacy. Students' self-efficacy was assessed with a 6-item scale adapted from a 7-item instrument developed from Jerusalem and Satow (1999). Cronbach's $\alpha$ in the original 7-item instrument ranges between .70 and .73 (Jerusalem and Satow 1999). Answers were given on a 5-point Likert scale ranging from "not at all true" (1) to "very true" (5). Mean scores were calculated over all items to measure self-efficacy.

Well-being. Students' well-being was assessed with 3 items on a 5-point scale. Students were asked how they enjoy school, whether they feel well at school, and whether they often feel lonely at school (in the style of Eder 2007). Answers were given on a 5-point Likert scale ranging from "I don't enjoy school" (1) to "I enjoy school very much" (5) respectively from "not at all true" (1) to "very true" (5). Cronbach's $\alpha$ in the sample is .6. Mean scores were calculated over all items (item 3 was recoded) to measure well-being.

\section{Analyses}

As pupils were clustered in classes, the authors checked whether variables significantly differed between classes. The authors conducted a multivariate analysis of variance with class as fixed factor and differences between pre-test and post-test sessions as dependent variables. The authors did not find significant differences between groups in intrinsic regulation, in introjected regulation, and in well-being (all $\mathrm{F}<1.36, p>.05$ ) but they found significant differences between groups in self-determination $(\mathrm{F}=7.83, p=.000)$, in identified regulation $(\mathrm{F}=3.61$, $p=.018)$, in external regulation $(\mathrm{F}=2.96, p=.039)$ and in self-efficacy ( $\mathrm{F}=3.69, p=.017$ ). Thus, the authors conducted all analyses split for pupils 
changing from first grade to second grade and for children changing from second grade to third grade and additionally controlled for gender-related effects.

The authors firstly analysed changes in self-determination, academic self-regulation, self-efficacy, and well-being calculating repeated measures ANOVAs. Secondly, the authors analysed correlations among self-determination, academic self-regulation, well-being, and self-efficacy. Thirdly, the authors conducted a path model to examine the impact of perceived self-determination, academic self-regulation, and school-related self-efficacy on subjective well-being.

\section{RESULTS}

Self-determination decreased significantly from first grade to second grade [F (128) $=9.86, p=.004]$, but not from second grade to third grade $[\mathrm{F}(135)=.55, p$ $=.816]$.

With respect to academic self-regulation, the authors were able to identify a decrease in intrinsic regulation from first to second grade $[\mathrm{F}(128)=4.32$, $p=.047]$ as well as for the children changing from second to third grade $[\mathrm{F}(135)=12.35, p=.001]$. The same phenomenon was observed in introjected regulation from first to second grade and from second to third grade $[\mathrm{F}(128)=5.19, p=.037 ; \mathrm{F}(135)=8.73$, $p=.006]$. For external regulation, scores decreased from second to third grade [F $(135)=13.45, p=.001]$. Identified regulation did not change significantly. Well-being did not change between first and second grade $[\mathrm{F}(128)=2.04, p=.164]$ but decreased between second grade and third grade $[\mathrm{F}(135)=$ 10.71, $p=.002$ ]. Self-efficacy decreased both from first to second grade $[\mathrm{F}(128)=6.99, p=.013]$ and from second to third grade [F (135) $=44.39, p=.000$ ]

Between classes, the authors found significant differences for self-determination, introjected regulation, intrinsic regulation, identified regulation, and self-efficacy $[t(27)>2.27, p<.031]$. In order to analyse possible gender differences, the authors included gender as a between subjects factor. The authors did not identify significant gender differences in self-determination [F (1) <.895, $p>.352$ ], intrinsic regulation $[F(1)=2.15, p>.151]$, introjected regulation $[F(1)=2.71, p=.109]$, identified regulation $[\mathrm{F}(1)=1.05, p>.314]$, external regulation [F $(1)=2.95, p>.095]$, well-being $[\mathrm{F}(1)<2.82$, $p>$.104] and self-efficacy [F (1) $<.923, p>$.345].

Self-determination was significantly correlated to intrinsic regulation $(r=.400, p=.000)$ and academic self-regulation strategies were correlated to each other: Intrinsic regulation was correlated significantly with introjected regulation $(r=.229, p=.039)$ and identified regulation $(r=.264, p=.017)$. Introjected regulation was significantly correlated with identified regulation $(r=.404, p=.000)$ and external regulation $(r=.453, p=.000)$. Identified regulation and external regulation were also significantly correlated $(r=.385$, $p=.000)$. Well-being was correlated with intrinsic regulation $(r=.345, p=.002)$, identified regulation $(r$ $=.245, p=.026)$, and self-efficacy $(r=.324, p=.003)$ (cp. Table 1: Coefficients from pre-test session, the post-test results are comparable).

As can be seen in Figure 1, perceived self-determination had a weak but significant impact on subjective well-being in the post-test session $(\beta=.17, p<.05)$ but not in the pre-test session. Academic self-regulation (a summary of self-regulation strategies defined by Müller et al. 2007) and school-related self-efficacy had a significant impact on subjective well-being in pre-test and post-test sessions $(\beta>.23, p<.05)$.

\section{DISCUSSIONS}

The study demonstrates that intervention programmes in primary schools can contribute to fostering teachers' autonomy support and to improving pupils' well-being in schools by considering motivational aspects, like their academic self-regulation and self-efficacy. 
Table 1. Correlations Between Variables in the Pre-test Session

\begin{tabular}{llllllll}
\hline & $(1)$ & $(2)$ & $(3)$ & $(4)$ & $(5)$ & $(6)$ & $(7)$ \\
\hline Self-determination (1) & 1 & $.400^{* *}$ & $.223^{*}$ & .137 & .004 & .077 & .184 \\
Intrinsic reg. (2) & $.400^{* *}$ & 1 & $.229^{*}$ & $.264^{*}$ & -.067 & .092 & $.345^{* *}$ \\
Introjected reg. (3) & $.223^{*}$ & $.229^{*}$ & 1 & $.404^{* *}$ & $.453^{* *}$ & -.056 & -.078 \\
Identified reg. (4) & .137 & $.264^{*}$ & $.404^{* *}$ & 1 & $.385^{* *}$ & .169 & $.245^{*}$ \\
External reg. (5) & .004 & -.067 & $.453^{* *}$ & $.385^{* *}$ & 1 & .007 & -.059 \\
Self-efficacy (6) & .077 & .092 & -.056 & .169 & .007 & 1 & $.324^{* *}$ \\
Well-being (7) & .184 & $.345^{* *}$ & -.078 & $.245^{*}$ & -.059 & $.324^{* *}$ & 1 \\
\hline
\end{tabular}

Notes: ** correlation significant with $p<.01{ }^{*}$ correlation significant with $p>.05$.

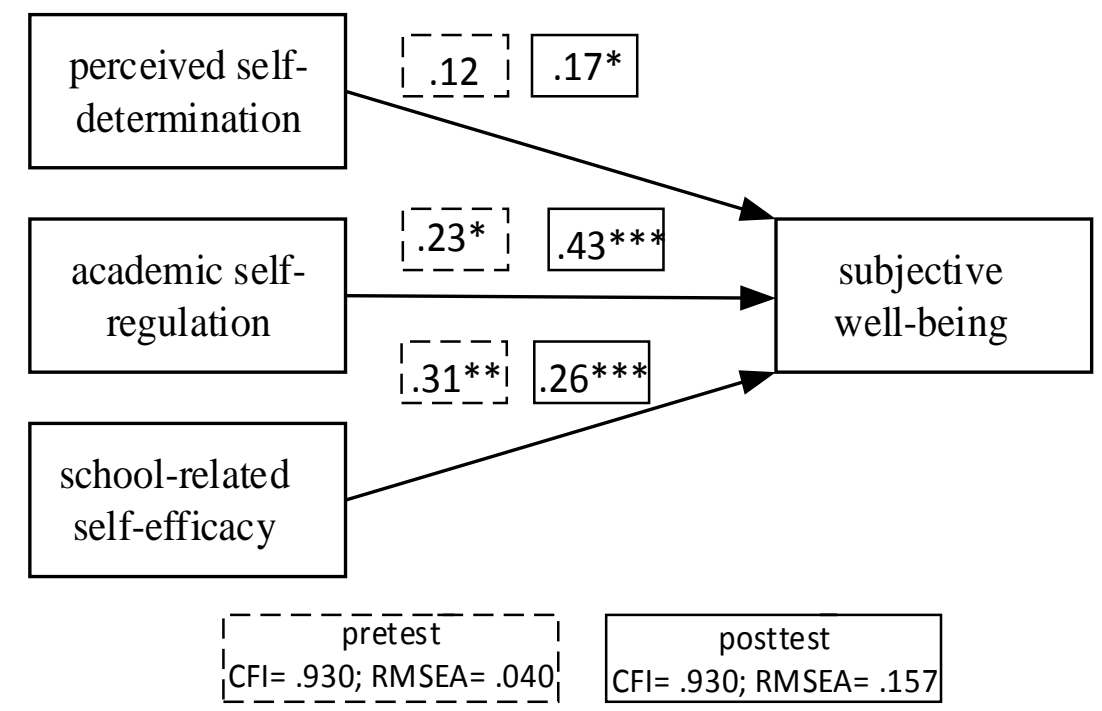

Figure 1. The Impact of Self-determination, Self-regulation, and Self-efficacy on Well-Being.

Especially in times when comparative assessments and achievement-related pressure have a serious impact on teaching and learning in schools (Ryan and Weinstein 2009), it seems essential to dedicate research to aspects like motivation and well-being as well.

The data reflect that the intervention could not stop a decrease in perceived self-determination from first grade to second grade in primary school whereas autonomy support remained stable in the other classes. An autonomy supportive teaching style avoids controlling strategies and is built around the inner motivational resources of the pupils (Reeve 2009). Learners experience autonomy in school, if they can pursue their interests and act in line with their intrinsic motivation. It is possible to foster self-determined forms of extrinsic motivation, although the impulse to act derives from another person-e.g., an authority as the teacher (Deci and Ryan 2012). When designing autonomy supportive contexts in schools, it is important to avoid excessive external control and pressure (Reeve, Deci, and Ryan 2004; Bartholomew et al. 2011; Reeve and Assor 2011). Although the main aim of the intervention was to help teachers to create opportunities for self-determined learning, some pupils reported that they perceived less autonomy support. One reason might be that these teachers felt under pressure by the intervention itself, 
an assumption that is stressed by research documenting that perceived pressure increases controlling teacher behaviour (Pelletier, Séguin-Lévesque, and Legault 2002; Pelletier and Sharp 2009). The authors’ programme included daily learning sessions outside the class context organised by the school team. It is possible that especially the educators of school beginners, who might yet not be able to trust in the learning abilities of their pupils, experienced a "loss of control" because they felt responsible for the progress of their pupils but had little influence on the actual work of their pupils during these autonomous learning phases. Teachers act in controlling ways, if they coerce their pupils to act, think, and feel in a desired way without acknowledging their individual perspective (Deci and Ryan 2012). Sanctions and gratifications as well as predetermined goals and rigid procedures are often perceived as controlling (Assor et al. 2005), but even without relying on these obviously pressure-inducing methods, teachers can use a certain style of communication and interaction with their pupils to coerce them into compliance (Reeve 2009; Reeve 2011). Concerning the authors' study, they specifically picked up the worries of these teachers in relation to the progress of their pupils to assist them in building self-determined settings.

According to the results, perceived autonomy did correlate with academic intrinsic regulation but against the intention, the intervention did not completely stop the decrease of intrinsic regulation and self-efficacy. Considering that the school beginners' intrinsic motivation in the sample is rather high, it seems feasible that maintaining this level can be difficult but further research is required to find out, if and to what extend a reduction of intrinsic academic motivation is inevitable (cf. Dresel et al. 2010). A positive result of the study was that identified regulation remained stable across the first years in primary school. Integrated types of motivation, like identified regulation, are only possible, if students have access to their motives, emotions, and meanings underpinning these actions, and therefore integrated regulation requires awareness, autonomy, and non-defensive processing (Weinstein, Przybylski, and Ryan 2013). Supporting pupils in this respect was one of the main aims of the intervention (Reeve et al. 2004). The reassuring conclusion for educators is that they can support their pupils' self-regulation and self-determination even when the focal activity is not interesting and by fostering their students' autonomy and motivation, teachers actively contribute to the well-being of their learners.

\section{LIMITATIONS AND FUTURE RESEARCH}

The present research requires the consideration of certain limits. The longitudinal design only focused on the development within two years in primary school and future studies are needed to document the trend throughout the time in primary school and to analyse the development of perceived autonomy, academic self-regulation, self-efficacy, and subjective well-being in transition phases as well. Moreover, the selectivity of the sample and the fact that the results relied on self-report measures of very young pupils, need to be considered, when interpreting the results. Future research integrating the perspective of teachers and using objective measures, like observers' reports, are essential to further analyse the impact of self-determination in schools (Ryan and Deci 2002).

\section{CONCLUSIONS}

The study demonstrates that perceived autonomy, academic self-regulation, and self-efficacy have an impact on school-related well-being right from the beginning of primary school, and therefore it seems important to dedicate further research to developing successful intervention programmes for teachers to foster these aspects and to make schools an even more pleasant experience for learners right from the start. 


\section{References}

Assor, A., H. Kaplan, Y. Kanat-Maymon, and G. Roth. 2005. "Directly Controlling Teacher Behaviors as Predictors of Poor Motivation and Engagement in Girls and Boys: The Role of Anger and Anxiety." Learning and Instruction 15(5):397-413.

Bandura, A. 1986. Social Foundations of Thought and Action. A Social Cognitive Theory. Englewood Cliffs, NJ: Prentice-Hall.

. 1997. Self-efficacy. The Exercise of Control. New York: W. H. Freeman and Company.

Bartholomew, K. J., N. Ntoumanis, R. M. Ryan, J. A. Bosch, and C. Thøgersen-Ntoumani. 2011. "Self-determination Theory and Diminished Functioning: The Role of Interpersonal Control and Psychological Need Thwarting.” Personality \& Social Psychology Bulletin 37(11):1459-1473.

Black, A. E. and E. L. Deci. 2000. "The Effects of Instructors' Autonomy Support and Students' Autonomous Motivation on Learning Organic Chemistry: A Self-determination Theory Perspective.” Science Education 84(6):740-756.

Boggiano, A. K. 1998. "Maladaptive Achievement Patterns: A Test of a Diathesis-Stress Analysis of Helplessness." Journal of Personality and Social Psychology 74(6):1681-1695.

Bouffard, T., M.-F. Marcoux, C. Vezeau, and L. Bordeleau. 2003. "Changes in Self-perceptions of Competence and Intrinsic Motivation Among Elementary Schoolchildren.” The British Journal of Educational Psychology 73(2):171-186.

Chatzisarantis, N. L. D. and M. S. Hagger. 2009. "Effects of an Intervention Based on Self-determination Theory on Self-reported Leisure-Time Physical Activity Participation.” Psychology \& Health 24(1):29-48.

Cheon, S. H. and J. Reeve. 2013. "Do the Benefits From Autonomy-Supportive PE Teacher Training Programs Endure?: A One-Year Follow-up Investigation.” Psychology of Sport and Exercise 14(4):508-518.

Corpus, J. H. and S. V. Wormington. 2014. "Profiles of Intrinsic and Extrinsic Motivations in Elementary School: A Longitudinal Analysis." The Journal of Experimental Education 82(4):480-501.

De Naeghel, J., H. Van Keer, M. Vansteenkiste, and Y. Rosseel. 2012. “The Relation Between Elementary Students' Recreational and Academic Reading Motivation, Reading Frequency, Engagement, and Comprehension: A Self-determination Theory Perspective.” Journal of Educational Psychology 104(4):1006-1021.

Deci, E. L. and R. M. Ryan. 1987. "The Support of Autonomy and the Control of Behavior." Journal of Personality and
Social Psychology 53(6):1024-1037.

_. 2000. "The 'What' and 'Why' of Goal Pursuits: Human Needs and the Self-determination of Behavior." Psychological Inquiry 11(4):227-268.

—. 2008. "Facilitating Optimal Motivation and Psychological Well-Being Across Life's Domains.” Canadian Psychology/Psychologie Canadienne 49(1):14-23.

_. 2012. "Motivation, Personality, and Development Within Embedded Social Contexts.” Pp. 85-107 in The Oxford Handbook of Human Motivation, edited by R. M. Ryan. New York: Oxford University Press.

—. 2016. "Optimizing Students' Motivation in the Era of Testing and Pressure: A Self-determination Theory Perspective.” Pp. 9-29 in Building Autonomous Learners. Perspectives From Research and Practice Using Self-determination Theory, edited by W. C. Liu, C. K. J. Wang, and R. M. Ryan. Singapore: Springer.

Deci, E. L., H. Eghrari, B. C. Patrick, and D. R. Leone. 1994. "Facilitating Internalization: The Self-determination Theory Perspective.” Journal of Personality 62(1):119-142.

Deci, E. L., R. Koestner, and R. M. Ryan. 1999. “A Meta-analytic Review of Experiments Examining the Effects of Extrinsic Rewards on Intrinsic Motivation.” Psychological Bulletin 125(6):627-668.

Dresel, M., M. Fasching, G. Steuer, and V.-D. Berner. 2010. "The Role and the Interplay of Classroom Goal Structures, Individual Motivation and General Intelligence for (Excellent) School Achievement in Elementary School Classrooms.” Talent Development \& Excellence 2(1):63-81.

Eder, F. 2007. Das Befinden von Kindern und Jugendlichen in der Österreichischen Schule. Befragung 2005 (Well-Being of Children and Juveniles in Austrian Schools. Reports 2005). Vol. 20. Innsbruck (u.a.): Studien Verl.

Fortier, M. S., R. J. Vallerand, and F. Guay. 1995. “Academic Motivation and School Performance: Toward a Structural Model.” Contemporary Educational Psychology 20(3):257-274.

Gottfried, A. E. 1990. "Academic Intrinsic Motivation in Young Elementary School Children.” Journal of Educational Psychology 82(3):525-538.

Grolnick, W. S. and R. M. Ryan. 1987. “Autonomy in Children's Learning: An Experimental and Individual Difference Investigation." Journal of Personality and Social Psychology 52(5):890-898.

Grolnick, W. S., R. M. Ryan, and E. L. Deci. 1991. "Inner Resources for School Achievement: Motivational Mediators of Children's Perceptions of Their Parents.” Journal of Educational Psychology 83(4):508-517.

Gurland, S. T. and W. S. Grolnick. 2005. "Perceived Threat, Controlling Parenting, and Children's Achievement 
Orientations.” Motivation and Emotion 29(2):103-121.

Hattie, J. 2009. Visible Learning. A Synthesis of Over 800 Meta-analyses Relating to Achievement. London, New York: Routledge.

Jang, H., J. Reeve, and E. L. Deci. 2010. “Engaging Students in Learning Activities: It Is Not Autonomy Support or Structure but Autonomy Support and Structure.” Journal of Educational Psychology 102(3):588-600.

Jang, H., J. Reeve, R. M. Ryan, and A. Kim. 2009. "Can Self-determination Theory Explain What Underlies the Productive, Satisfying Learning Experiences of Collectivistically Oriented Korean Students?” Journal of Educational Psychology 101(3):644-661.

Jerusalem, M. and L. Satow. 1999. "Schulbezogene Selbstwirksamkeitserwartung” (School-Related Self-efficacy Beliefs). Pp. 15-16 in Skalen zur Erfassung von Lehrer- und Schülermerkmalen. Dokumentation der Psychometrischen Verfahren im Rahmen der Wissenschaftichen Begleitung des Modellversuchs Selbstwirksame Schulen (Scales to Measure Teachers' and Pupils' Variables. Documentation of Psychometric Instruments Used in the Scientific Guidance of the Experiment Self-efficacy in Schools), edited by R. Schwarzer and M. Jerusalem. Berlin: Free University.

Kasser, T. and R. M. Ryan. 1996. "Further Examining the American Dream: Differential Correlates of Intrinsic and Extrinsic Goals.” Personality and Social Psychology Bulletin 22(3):280-287.

Lepper, M. R., J. H. Corpus, and S. S. Iyengar. 2005. "Intrinsic and Extrinsic Motivational Orientations in the Classroom: Age Differences and Academic Correlates.” Journal of Educational Psychology 97(2):184-196.

Miserandino, M. 1996. "Children Who Do Well in School: Individual Differences in Perceived Competence and Autonomy in Above-Average Children.” Journal of Educational Psychology 88(2):203-214.

Müller, F. H., B. Hanfstingl, and I. Andreitz. 2007. Skalen zur Motivationalen Regulation Beim Lernen von Schülerinnen und Schülern: Adaptierte und Ergänzte Version des Academic Self-regulation Questionnaire (SRQ-A) nach Ryan \& Connell [Scales for Pupils' Motivational Regulation of Learning: Adapted and Supplemented Version of the Academic Self-regulation Questionnaire (SRQ-A) by Ryan \& Connell]. Retrieved (http://ius.aau.at/wp-content/uploads/2016/01/IUS_Forschu ngsbericht_1_Motivationsskalen.pdf).

Pajares, F., and T. C. Urdan, eds. 2006. Adolescence and Education, Self-efficacy Beliefs of Adolescents. Greenwich, CT: IAP-Information Age Pub.

Pelletier, L. G. and E. C. Sharp. 2009. "Administrative Pressures and Teachers' Interpersonal Behaviour in the
Classroom." Theory and Research in Education 7(2):174-183.

Pelletier, L. G., C. Séguin-Lévesque, and L. Legault. 2002. "Pressure From Above and Pressure From Below as Determinants of Teachers' Motivation and Teaching Behaviors.” Journal of Educational Psychology 94(1):186-196.

Pelletier, L. G., M. A. Rocchi, R. J. Vallerand, E. L. Deci, and R. M. Ryan. 2013. "Validation of the Revised Sport Motivation Scale (SMS-II)." Psychology of Sport and Exercise 14(3):329-341.

Reeve, J. 2009. "Why Teachers Adopt a Controlling Motivating Style Toward Students and How They Can Become More Autonomy Supportive.” Educational Psychologist 44(3):159-175.

—. 2011. "Teaching in Ways That Support Student's Autonomy.” Pp. 90-103 in Empirical Research in Teaching and Learning. Contributions From Social Psychology, edited by D. J. Mashek and E. Y. Hammer. Malden, MA: Wiley-Blackwell.

Reeve, J. and A. Assor. 2011. "Do Social Institutions Necessarily Suppress Individuals' Need for Autonomy? The Possibility of Schools as Autonomy-Promoting Contexts Across the Globe.” Pp. 111-132 in Cross-Cultural Advancements in Positive Psychology. Vol. 1, Human Autonomy in Cross-Cultural Context. Perspectives on the Psychology of Agency, Freedom, and Well-Being, edited by V. I. Chirkov, R. M. Ryan, and K. M. Sheldon. Dordrecht, New York: Springer.

Reeve, J. and S. H. Cheon. 2014. "An Intervention-Based Program of Research on Teachers’ Motivating Styles.” Pp. 293-339 in Advances in Motivation and Achievement. Vol. 18, Motivational Interventions, edited by S. A. Karabenick and T. C. Urdan. Bingley: Emerald Group Publishing Limited.

Reeve, J., E. L. Deci, and R. M. Ryan. 2004. "Self-determination Theory: A Dialectical Framework for Understanding Socio-Cultural Influences on Student Motivation.” Pp. 31-60 in Big Theories Revisted, edited by D. M. McInerney and S. van Etten. Greenwich, CT: Information Age Press.

Reeve, J., H. Jang, D. Carrell, S. Jeon, and J. Barch. 2004. “Enhancing Students' Engagement by Increasing Teachers' Autonomy Support.” Motivation and Emotion 28(2):147-169.

Ryan, R. M. 1993. “Agency and Organization: Intrinsic Motivation, Autonomy and the Self in Psychological Development." Pp. 1-56 in Nebraska Symposium on Motivation. Vol. 40, Developmental Perspectives on Motivation. 40th Nebraska Symposium on Motivation: Papers, edited by J. E. Jacobs. Lincoln: University of 
Nebraska Press.

Ryan, R. M. and E. L. Deci. 2002. "An Overview of Self-determination Theory: An Organismic-Dialectic Perspective.” Pp. 3-33 in Handbook of Self-determination Research, edited by E. L. Deci and R. M. Ryan. Rochester, NY: University of Rochester Press.

—. 2013. "Toward a Social Psychology of Assimilation: Self-determination Theory in Cognitive Development and Education.” Pp. 191-207 in Self-regulation and Autonomy. Social and Developmental Dimensions of Human Conduct, edited by B. W. Sokol, F. M. E. Grouzet, and U. Müller. Cambridge, England: Cambridge University Press.

Ryan, R. M. and J. P. Connell. 1989. "Perceived Locus of Causality and Internalization: Examining Reasons for Acting in Two Domains." Journal of Personality and Social Psychology 57(5):749-761.

Ryan, R. M. and J. Stiller. 1991. "The Social Contexts of Internalization: Parent and Teacher Influences on Autonomy, Motivation and Learning.” Pp. 115-149 in Advances in Motivation and Achievement. A Research Annual, edited by M. L. Maehr. Greenwich, CT (u.a.): JAI Press.

Ryan, R. M. and N. Weinstein. 2009. "Undermining Quality Teaching and Learning: A Self-determination Theory Perspective on High-Stakes Testing.” Theory and Research in Education 7(2):224-233.

Schunk, D. H. and F. Pajares. 2005. "Competence Beliefs in Academic Functioning." Pp. 85-104 in Handbook of Competence and Motivation, edited by A. J. Elliot and C. S. Dweck. New York: Guilford Press.

Sierens, E., M. Vansteenkiste, L. Goossens, B. Soenens, and F. Dochy. 2009. "The Synergistic Relationship of Perceived Autonomy Support and Structure in the Prediction of Self-regulated Learning." The British Journal of Educational Psychology 79(1):57-68.

Skinner, E. A., T. A. Kindermann, J. P. Connell, and J. G. Wellborn. 2009. "Engagement and Disaffection as an Organizational Construct in the Dynamics of Motivational Development.” Pp. 223-245 in Educational Psychology Handbook Series, Handbook of Motivation at School, edited by K. R. Wentzel and A. Wigfield. New York, London: Routledge.

Soenens, B., E. Sierens, M. Vansteenkiste, F. Dochy, and L. Goossens. 2012. "Psychologically Controlling Teaching: Examining Outcomes, Antecedents, and Mediators.” Journal of Educational Psychology 104(1):108-120.

Spinath, B. and R. Steinmayr. 2008. "Longitudinal Analysis of Intrinsic Motivation and Competence Beliefs: Is There a Relation Over Time?” Child Development 79(5):1555-1569.

Su, Y.-L. and J. Reeve. 2011. "A Meta-Analysis of the
Effectiveness of Intervention Programs Designed to Support Autonomy." Educational Psychology Review 23(1):159-188.

Tessier, D., P. Sarrazin, and N. Ntoumanis. 2010. “The Effect of an Intervention to Improve Newly Qualified Teachers' Interpersonal Style, Students Motivation and Psychological Need Satisfaction in Sport-Based Physical Education.” Contemporary Educational Psychology 35(4):242-253.

Thøgersen-Ntoumani, C. and N. Ntoumanis. 2006. "The Role of Self-determined Motivation in the Understanding of Exercise-Related Behaviours, Cognitions and Physical Self-evaluations.” Journal of Sports Sciences 24:393-404.

Usher, E. L. and F. Pajares. 2008. "Sources of Self-efficacy in School: Critical Review of the Literature and Future Directions." Review of Educational Research 78(4):751-796.

Vallerand, R. J., M. S. Fortier, and F. Guay. 1997. "Self-determination and Persistence in a Real-Life Setting: Toward a Motivational Model of High School Dropout.” Journal of Personality and Social Psychology. 72(5):1161-1176.

Vansteenkiste, M., E. Sierens, B. Soenens, K. Luyckx, and W. Lens. 2009. "Motivational Profiles From a Self-determination Perspective: The Quality of Motivation Matters.” Journal of Educational Psychology 101(3):671-688.

Vansteenkiste, M., J. Simons, W. Lens, K. M. Sheldon, and E. L. Deci. 2004. "Motivating Learning, Performance, and Persistence: The Synergistic Effects of Intrinsic Goal Contents and Autonomy-Supportive Contexts.” Journal of Personality and Social Psychology 87(2):246-260.

Weinstein, N., A. K. Przybylski, and R. M. Ryan. 2013. "The Integrative Process: New Research and Future Directions.” Current Directions in Psychological Science 22(1):69-74.

Williams, G. C. and E. L. Deci. 1996. "Internalization of Biopsychosocial Values by Medical Students. A Test of Self-determination Theory." Journal of Personality and Social Psychology 70(4):767-779.

\section{Bios}

Daniela Martinek, Ph.D., assistant professor, head of Educational Science Department of the School of Education, University of Salzburg, Austria; research fields: teacher education, teaching profession, self-determination, motivation, autonomous teaching and learning.

Ulrike Kipman, Ph.D. in philosophy, science, and law, researcher, University of Salzburg, Austria; research fields: diagnostics, decision-making, probability, activity-oriented education. 